General Thoracic

Surgery

\title{
Promoter methylation of the $h M L H 1$ gene and protein expression of human mutL homolog 1 and human mutS homolog 2 in resected esophageal squamous cell carcinoma
}

\author{
Ching Tzao, MD, PhD, ${ }^{a}$ Han-Sui Hsu, MD, ${ }^{\mathrm{b}}$ Guang-Huan Sun, MD, PhD, ${ }^{c}$ Hsiou-Lei Lai, BS, ${ }^{a}$ \\ Yi-Ching Wang, PhD, ${ }^{d}$ Ho-Jui Tung, PhD, ${ }^{e}$ Cheng-Ping Yu, MD, PhD, ${ }^{f}$ \\ Yeung-Leung Cheng, MD, PhD, and Shih-Chun Lee, $\mathrm{MD}^{\mathrm{a}}$
}

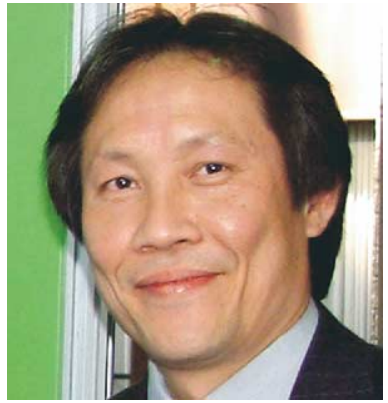

Dr Tzao
Additional material is available online.
From the Division of Thoracic Surgery, ${ }^{\mathrm{a}}$ the Department of Surgery, ${ }^{\mathrm{c}}$ and the Department of Pathology, ${ }^{\mathrm{f}}$ Tri-Service General Hospital, National Defense Medical Center; the Division of Thoracic Surgery, Veterans General Hospital $^{\text {b }}$, the Department of Life Sciences, National Taiwan Normal University ${ }^{\mathrm{d}}$; and the Department of Humanity and Social Studies, National Defense Medical Center, ${ }^{\text {e }}$ Taipei, Taiwan, Republic of China.

Supported by grants from the National Science Council, Taiwan, ROC (NSC 93-1314B-016-063), and the Research Foundation, TriService General Hospital (TSGH-C91-22).

Read at the Eighty-fifth Annual Meeting of The American Association for Thoracic Surgery, San Francisco, Calif, April 10-13, 2005.

Received for publication March 25, 2005; revisions received May 15, 2005; accepted for publication June 7, 2005.

Address for reprints: Shih-Chun Lee, MD, Division of Thoracic Surgery, National Defense Medical Center, 325, Section 2, Cheng Gong Road, Nei Hu, Taipei, Taiwan 114, Republic of China (E-mail: ylc116@yahoo. com.tw).

J Thorac Cardiovasc Surg 2005;130:1371-7 $0022-5223 / \$ 30.00$

Copyright $\odot 2005$ by The American Association for Thoracic Surgery

doi:10.1016/j.jtcvs.2005.06.004
Objective: Aberrant expression of mismatch repair genes, such as human mutL homolog 1 ( $h M L H 1$ ) and human mutS homolog 2 (hMSH2), are common in some human cancers, and promoter methylation is believed to inactivate expression of $h M L H 1$. We investigated whether promoter methylation is involved in loss of hMLH1 protein and whether aberrant expression of hMLH1 and $\mathrm{hMSH} 2$ protein is related to prognosis after resection for esophageal squamous cell cancer.

Methods: We analyzed promoter methylation of $h M L H 1$ using methylation-specific polymerase chain reaction and hMLH1 and hMSH2 protein by using immunohistochemistry in 60 resected tumor specimens. The Pearson $\chi^{2}$ test was used to compare expression of hMLH1 and hMSH2 protein among patients with different clinicopathologic parameters. Concordance analysis was performed between $h M L H 1$ methylation and its protein expression.

Results: Loss of hMLH1 and hMSH2 protein was found in $43(72 \%)$ and $39(65 \%, P=$ $.06)$ of 60 resected specimens, respectively. hMLH1 protein correlated well with tumor staging $(P<.0001)$, depth of tumor invasion $(P=.008)$, and nodal involvement $(P<$ .0001) but not with distant metastasis, whereas hMSH2 did not show correlation with any of these parameters. A concordance rate of $83.3 \%$ was present between expression of hMLH1 protein and its promoter methylation $(P<.001)$.

Conclusions: Aberrant expression of hMLH1 and hMSH2 protein is frequently associated with the presence of esophageal squamous cell carcinoma, and expression of hMLH1 protein is a better prognostic predictor than is expression of hMSH2 protein. Promoter methylation is one of the mechanisms responsible for loss of hMLH1 protein in esophageal squamous cell cancer.

$\mathrm{P}$ romoter methylation is one of the most important mechanisms leading to inactivation of gene expression and has been known to cause aberrant expression of some important tumor suppressor genes, such as $p 16,{ }^{1}$ E-cadherin, ${ }^{2}$ and the von Hippel Lindau gene. ${ }^{3}$ Promoter methylation has been implicated in the carcinogenic process in many cancers, including gastric cancer, colorectal cancer, breast cancer, lung cancer, ovarian cancer, bladder cancer, and oral cancers. ${ }^{4,5}$ 


\section{Abbreviations and Acronyms \\ hMLH1 = human mutL homolog 1 \\ hMSH2 = human mutS homolog 2 \\ MMR = mismatch repair \\ $\mathrm{PCR}=$ polymerase chain reaction}

Mismatch repair (MMR) is an important mechanism by which cells correct errors in DNA replication during proliferation. ${ }^{6}$ Cells with MMR defects show mutation rates up to 1000 -fold greater than those observed in normal cells. ${ }^{6}$ Two MMR genes, human mutL homolog $1(h M L H I)$ and human mutS homolog 2 ( $h M S H 2$ ), have been cloned and demonstrated to participate in DNA MMR. ${ }^{7,8}$ The mutant phenotype has been detected in tumors from patients with hereditary nonpolyposis colorectal cancer, ${ }^{9}$ as well as in lung, ${ }^{10}$ ovarian, ${ }^{11}$ head and neck, ${ }^{12}$ and gastrointestinal cancers, including gastric cancer ${ }^{13}$ and adenocarcinoma of the esophagus. ${ }^{14}$ The loss of corresponding protein is seen in almost all of the tumors with germline MMR gene mutation. ${ }^{15}$

The loss of $h M L H I$ expression has been shown to correlate with cytosine methylation of $\mathrm{CpG}$ islands regions in its promoter region in colon cancer cell lines and tissues. ${ }^{16,17}$ Promoter methylation associated with loss of the hMLH1 protein has been found in some MMR-defective colorectal and endometrial cancer cell lines in which mutations in the MMR genes, including $h M S H 2, h M L H 1, h P M S 2$, and $h P M S 1$, were absent. ${ }^{17,18}$ Interestingly, these results demonstrate that the promoter of $h M S H 2$ is rarely methylated, indicating that aberrant methylation of the $h M L H 1$ promoter is potentially a very important mechanism in the inactivation of the MMR system in human cancers. ${ }^{17,18}$

Little is known about whether promoter methylation of $h M L H 1$ is associated with loss of hMLH1 protein and the role of promoter methylation in tumorigenesis of squamous cell carcinoma of the esophagus. There are no correlative studies of aberrant expression of these MMR genes and the prognosis of esophageal squamous cell cancer. We examined promoter methylation of $h M L H 1$ and expression of hMLH1 and hMSH2 protein in squamous cell carcinoma of the esophagus in relation to prognosis.

\section{Methods}

\section{Study Population and Tumor Samples}

After esophagectomy for 60 patients with squamous cell carcinoma, archival paraffin-embedded tissue blocks of all primary tumor specimens and 20 of 60 matched normal mucosa control specimens were collected from January 1998 through December 2003. The study was reviewed and approved by the institution's surveillance committee, which allowed us to get access to patients' medical records and to obtain tissue samples and pertinent follow-up data. From review of medical records, clinical information was collected, and TNM status was recorded on the basis of the American Joint Committee on Cancer staging system ${ }^{19}$ for esophageal cancer. Survival and follow-up data were obtained from the Institutional Cancer Registry.

\section{DNA Extraction and Methylation-specific Polymerase Chain Reaction Assay for $h M L H 1$}

Serial $5-\mu \mathrm{m}$ sections were cut from formalin-fixed, paraffinembedded tissue blocks. All slides were stained with hematoxylin and eosin, and one of the slides was used as a guide to localize tumor regions. The tumor cells were microdissected from 3 slides of serial sections. After deparaffinization in xylene, genomic DNA of recovered tumor cells was prepared by using proteinase $\mathrm{K}$ digestion and phenol-chloroform extraction, followed by ethanol precipitation. The promoter methylation status of the $h M L H 1$ gene of all tumor samples and their normal mucosa control samples was determined by means of chemical treatment with sodium bisulfite and subsequent methylation-specific polymerase chain reaction (PCR) analysis, as described by Herman and colleagues. ${ }^{20}$ For bisulfite treatment of DNA used for methylation-specific PCR, extracted DNA $(1 \mu \mathrm{g})$ in a volume of $50 \mu \mathrm{L}$ was denatured with $\mathrm{NaOH}$ (final concentration, $0.2 \mathrm{~mol} / \mathrm{L}$ ) for 10 minutes at $37^{\circ} \mathrm{C}$ for samples with nanogram quantities of human DNA, and $1 \mu \mathrm{g}$ of salmon sperm DNA (Sigma-Aldrich Corporation, St Louis, Mo) was added as a carrier before modification. Thirty microliters of 10 $\mathrm{mmol} / \mathrm{L}$ hydroquinone (Sigma-Aldrich) and $520 \mu \mathrm{L}$ of $3 \mathrm{~mol} / \mathrm{L}$ sodium bisulfite (Sigma-Aldrich) at $\mathrm{pH} 5$, both freshly prepared, were added and mixed, and samples were incubated under mineral oil at $50^{\circ} \mathrm{C}$ for 16 hours. Modified DNA was purified by using the Wizard DNA purification resin according to the manufacturer (Promega Corp, Madison, Wis) and eluted into $50 \mu \mathrm{L}$ of water. Modification was completed by $\mathrm{NaOH}$ (final concentration, 0.3 $\mathrm{mol} / \mathrm{L}$ ) treatment for 5 minutes at room temperature, followed by ethanol preditation. DNA was resuspended in water and stored at $-20^{\circ} \mathrm{C}$ until used for PCR amplification. Primer sequences of $h M L H 1$ for the unmethylated reaction were $5^{\prime}$-TTTTGATGTAGATGTTTTATTAGGGTTGT-3' (sense) and 5'-ACCACCTCATCATAACTACCCACA-3' (antisense), and for the methylated reaction, they were 5'-ACGTAGACGTTTTATTAGGGTCGC-3' (sense) and 5'CCTCATCGT AAC-TACCCGCG-3' (antisense). ${ }^{9}$ Paraffin-embedded samples were amplified first with flanking PCR primers that amplify bisulfite-modified DNA but that would not preferentially amplify methylated or unmethylated DNA. The primers used were 5'-GAGTAGTTTTTTTTTTAGGAGTGAAG-3'27 (sense) and 5'AAAAACTATAAAACCCTATACCTAATCTA-3' (antisense). ${ }^{9}$ PCR was performed for 40 cycles at an annealing temperature of $65^{\circ} \mathrm{C}$ and $62^{\circ} \mathrm{C}$ for unmethylated and methylated reactions, respectively, by using $50 \mathrm{ng}$ of bisulfite-modified DNA. All PCRs were performed with positive controls for both unmethylated and methylated alleles and no DNA control. A ratio of greater than 0.5 was defined as aberrant methylation.

\section{Analysis of Protein Expression: Immunohistochemistry Assay \\ Paraffin blocks of tumors were cut into 5- $\mu \mathrm{m}$ slices and then processed by using standard deparaffinization and rehydration techniques. After antigen retrieval with microwave heating, all tissue sections on slides were immunostained according to instruc-}



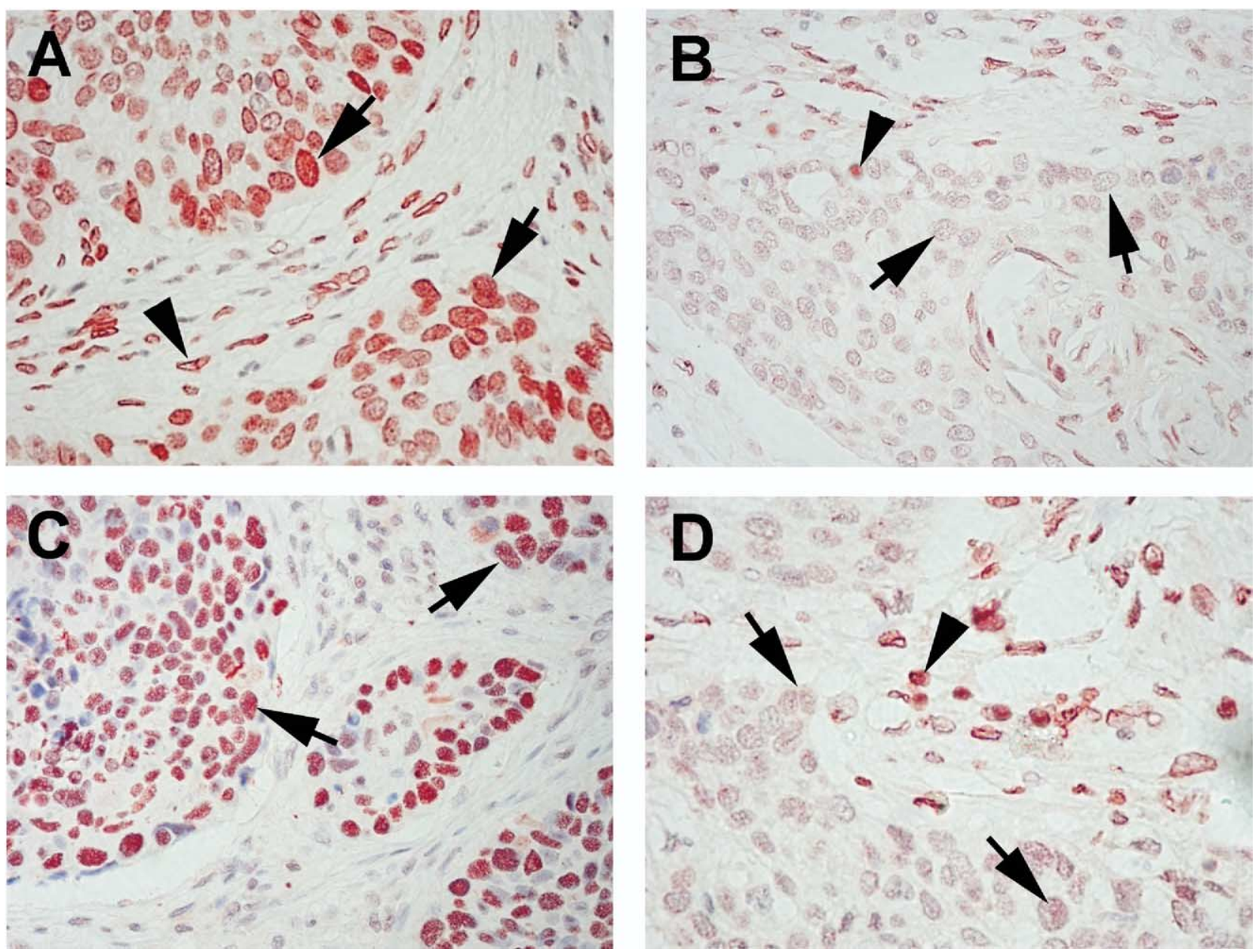

Figure 1. Immunostaining of hMLH1 and hMSH2 for a resected specimen of esophageal squamous cell carcinoma. A, Positive staining was detected in nuclei of tumor cells (arrows) and in vascular endothelial cells (arrowhead) for hMLH1. B, Tumor cells stained negatively (arrows), whereas an infiltrating lymphocyte stained positively (arrowhead) for hMLH1. C, Positive staining for hMSH2 was detected in the nuclei of tumor cells (arrows). D, Tumor cells stained negatively (arrows), whereas an infiltrating lymphocyte stained positively (arrowhead) for hMSH2. Positive nuclear staining in lymphocytes serves as an internal positive control for immunostaining of hMLH1 and hMHS2, respectively.

tions from the antibody suppliers. The monoclonal antibody used was G168-728 (1:250; PharMingen, San Diego, Calif) for the hMLH1 protein and FE11 (1:50; Oncogen Science, Cambridge, Mass) for the hMSH2 protein, respectively. The binding of primary antibody was visualized with a detection system (DAKO LSAB Kit K675; DakoCytomation California Inc, Carpinteria, Calif). The normal staining pattern for hMLH1 and hMSH2 is nuclear. Tumor cells that exhibited an absence of nuclear staining in the presence of nonneoplastic cells or infiltrating lymphocytes with nuclear staining were considered to have an abnormal pattern. Staining results were examined by 2 observers blinded to the status of the molecular analyses.

\section{Statistical Analysis}

The Pearson $\chi^{2}$ test was used to compare expression of hMLH1 and hMHS2 protein and methylation status of $h M L H 1$ among patients undergoing esophagectomy for esophageal squamous cell carcinoma with different clinicopathologic characteristics, including age, stage, and overall TNM category. Comparison of age between patients with and without alterations was made by using the 2-sample $t$ test. The Kaplan-Meier method was used to estimate the probability of survival as a function of time and the median survival. ${ }^{21}$ The log-rank test was used to assess the significance of difference between pairs of survival probabilities. $^{22}$ 

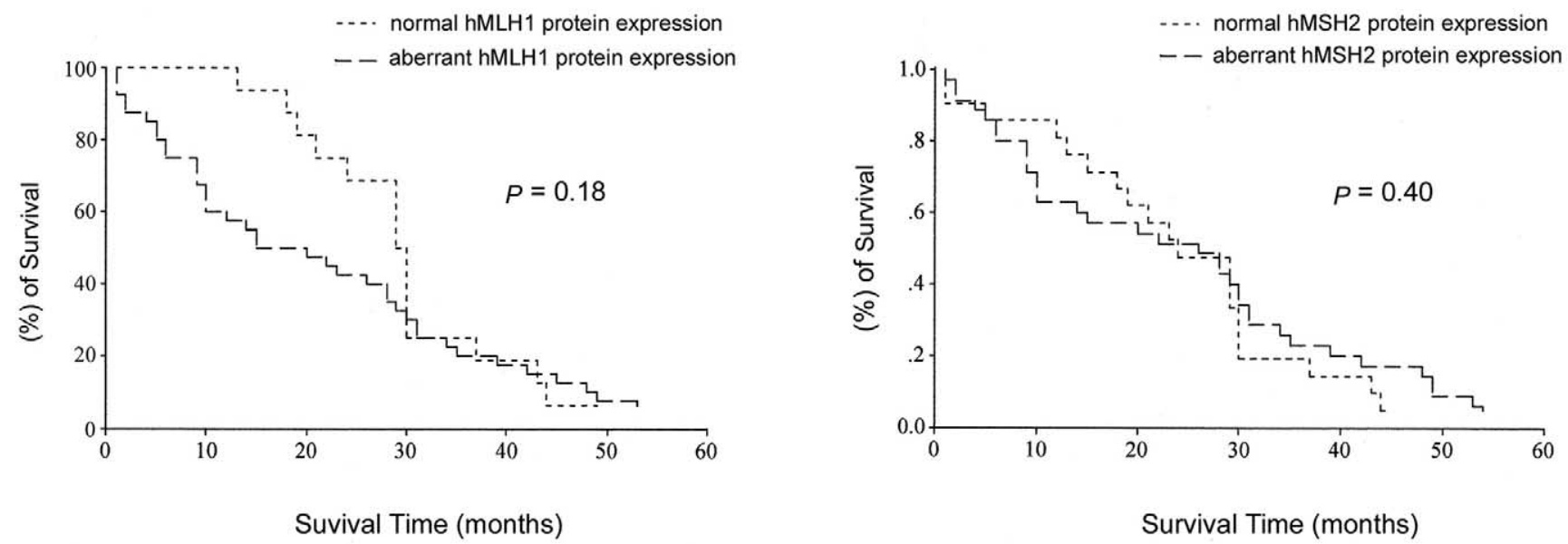

Figure 2. Kaplan-Meier survival curve with log-rank test for 60 patients followed for 5 years after resection for esophageal squamous cell carcinoma. Comparison of survival between patients with normal and aberrant expression of hMLH1 and hMSH2 protein was shown in A and B, respectively. Ninety-five percent confidence intervals for the hMLH1 and hMSH2 groups were 25.6 to 32.4 and 19.2 to 38.8 months, respectively.

\section{Results}

Expression of hMLH1 and hMSH2 Protein in Relation to Patients' Clinicopathologic Parameters and Survival Clinical information for 60 patients undergoing esophagectomy for squamous cell carcinoma of the esophagus is summarized in Table E1. The association of altered expression of hMLH1 and hMSH2 protein with patients' clinicopathologic parameters is summarized in Table E2. Aberrant expression of hMLH1 (Figure 1,B) and hMSH2 (Figure 1, $D$ ) protein was observed in $43(72 \%)$ and $39(65 \%)$ patients, respectively $(P=.06)$. Aberrant expression for hMLH1 protein correlated well with stage $(P<.0001)$, T status $(P$ $=.008)$, and $\mathrm{N}$ status $(P<.0001)$, whereas none of the patients' clinicopathologic parameters showed significant correlation with aberrant expression of $\mathrm{hMSH} 2$ protein.
Median survivals in months were as follows: $24 \pm 3.7$ and $26 \pm 7.7$ (standard error) for patients with unmethylated and methylated $h M L H I$ genes $(P=.24) ; 29 \pm 1.7$ and $15 \pm 6.3$ for patients with normal and aberrant expression of hMLH1 protein $(P=.18)$; and $29 \pm 5.0$ and $23 \pm 6.7$ for patients with normal and aberrant expression of hMSH2 protein, respectively $(P=.40)$. No significant difference in survival existed between patients with normal and aberrant expression of hMLH1 $(P=.18)$ or hMSH2 protein $(P=.40$, Figure 2).

Promoter Methylation of $h M L H 1$ and its Association With Clinicopathologic Parameters

A representative result is shown in Figure 3. All normal mucosa control specimens showed only unmethylated

\section{$\begin{array}{lllll}\text { Marker } & \mathrm{N}(\mathrm{Pt} .1) & \mathrm{T}(\mathrm{Pt} .1) & \mathrm{T}(\mathrm{Pt} .2) & \mathrm{T}(\mathrm{Pt} .3)\end{array}$}

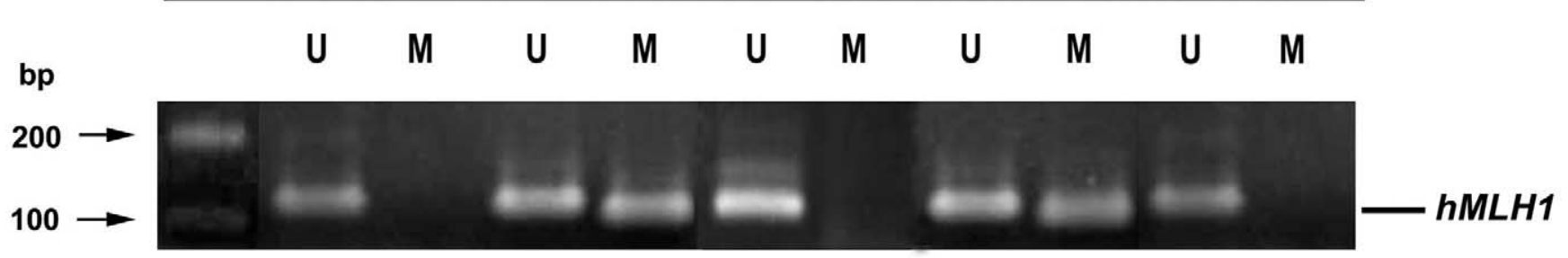

Figure 3. Representative results of promoter methylation for $h M H L 1$. Primer sets used for amplification were designated as $\boldsymbol{U}$ for the unmethylated product and $\boldsymbol{M}$ for methylated genes. The data for lymphocytes containing unmethylated $h M L H 1$ were shown for the experimental control. $N$ represents normal mucosa sample, and $T$ represents tumor sample. Tumor samples for patients 1 and 3 showed methylated hMLH1, whereas normal mucosa from patient 1, tumor sample from patient 2 , and lymphocytes showed only unmethylated $h M L H 1$. Lymphocytes for unmethylated gene control specimens were harvested from 10 healthy volunteers. 
hMLH1 (data not shown). Thirty-seven (62\%) tumor specimens showed methylated $h M L H 1$ (Table E2). In contrast to the correlative analysis of protein expression, the methylation status of $h M L H 1$ correlated well with stage $(P=.024)$ and $\mathrm{N}$ status $(P=.02)$ but not with $\mathrm{T}$ or $\mathrm{M}$ status (Table E2).

\section{Correlation of Promoter Methylation With Aberrant Protein Expression of $\mathbf{h M L H I}$}

A concordance rate of $83.3 \%$ was observed between promoter methylation and aberrant protein expression of hMLH1 $(P<.001$, Table E3), indicating that promoter methylation might play an important role in the inactivation of protein expression for $h M L H 1$.

\section{Discussion}

Impaired MMR DNA replication often leads to a mutant phenotype of human cells ${ }^{6}$ and is believed to be involved in carcinogenesis in some human cancers. ${ }^{9-14}$ Promoter methylation is an important mechanism that causes inactivation of expression of DNA MMR genes, such as $h M L H 1$, in human cancers. ${ }^{10,12,13}$ Little is known about whether promoter methylation of $h M L H 1$ is associated with loss of hMLH1 protein and whether aberrant expression of hMLH1 protein is involved in tumorigenesis of squamous cell carcinoma of the esophagus. Furthermore, there are no correlative studies of aberrant expression of these MMR genes and the prognosis of esophageal squamous cell cancer. To address the above questions, we designed this study to investigate promoter methylation of $h M L H I$ and expression of hMLH1 and hMSH2 protein in squamous cell carcinoma of the esophagus in relation to prognosis.

Aberrant expression of hMLH1 protein was observed in a considerable number of our patients within the early and late stages, suggesting that loss of hMLH1 protein is an early event in tumorigenesis of esophageal squamous cell cancer, and it persists as tumor progresses. Loss of hMSH2 protein was also observed in a considerable number of patients, but it did not show significant correlation between any of the patients' clinicopathologic parameters. In contrast, aberrant expression of hMLH1 protein correlated well with patients' overall stage, $\mathrm{T}$ status, and $\mathrm{N}$ status. These results suggest that expression of hMLH1 protein is a better prognostic predictor than expression of $\mathrm{hMSH} 2$ protein. Intriguingly, survival analysis did not show significant correlation between patients with normal and aberrant expression of hMLH1 or hMSH2 protein. We speculated that absence of correlation between survival and expression of hMLH1 or hMSH2 protein might be attributed to the small sample size studied.

A concordance of $83.3 \%$ observed between promoter methylation of $h M L H l$ and its protein expression implies that promoter methylation is an important mechanism that is responsible for the inactivation of protein expression of
hMLH1. Within the remaining $16.7 \%$ of discordance, 8 $(13.3 \%)$ tumor samples presented with unmethylated promoter of $h M L H 1$ but aberrant expression of hMLH1 protein, suggesting that there might be mechanisms other than promoter methylation leading to inactivation of gene expression, such as loss of heterozygosity or splicing of mRNA transcript, as reported previously. ${ }^{9,23}$ Our results support previous results that suggest promoter methylation of the hMLHI as a major mechanism responsible for silencing of its gene expression and an active player in carcinogenesis for some human cancers. ${ }^{8-12}$ The majority of previous studies did not correlate results from molecular analyses with patients' clinicopathologic parameters or outcome, as we did in the current study.

Promoter methylation with aberrant expression of $h M L H 1$, but not $h M S H 2$, has been reported in gastrointestinal cancers, including colorectal and gastric cancers. ${ }^{5,17}$ There are limited reports discussing the role of promoter methylation and altered expression of hMLH1 or hMSH2 protein in esophageal cancer. Evans and coworkers ${ }^{14}$ demonstrated loss of both hMLH1 and $\mathrm{hMSH} 2$ protein in $78 \%$ (21/27) of resected esophageal adenocarcinomas, but they concluded that protein expression was not associated with tumor grade, pathologic stage, or patient survival. Promoter methylation was not investigated in their study. In comparison, we also demonstrated a high frequency of aberrant protein expression of both hMLH1 and hMSH2 and promoter methylation of hMLH1. Unlike their results, a good correlation between aberrant protein expression of $h M L H 1$ and tumor stage and individual $\mathrm{T}$ and $\mathrm{N}$ status was observed in our study. In addition, we showed a significant correlation between promoter methylation of $h M L H l$ with patients' stage and $\mathrm{N}$ status. Differences in these 2 results might be attributed to different types of cancers, different ethnic groups, and different sample sizes studied or to patient selection.

Results from studies related to methylation and protein expression of the $h M L H 1$ gene in squamous cell cancer of the esophagus remain controversial. Nie and associates ${ }^{24}$ showed a frequency of $h M L H 1$ methylation in $5(20 \%)$ of 24 resected esophageal squamous cell carcinomas, but they did not describe its protein expression. On the other hand, Hayashi and colleagues ${ }^{25}$ reported a low frequency of $20 \%$ for aberrant hMLH1 protein expression in 30 resected esophageal squamous cell carcinoma samples. In that study only 7 of the 30 resected tumor samples were analyzed for methylation of the $h M L H 1$ gene, and none of them was methylated. In contrast, Kubo and coworkers ${ }^{26}$ reported a high frequency (66.7\%) of $h M L H 1$ methylation and its protein expression in 34 esophageal carcinomas associated with other primary cancers but did not clarify their frequencies in esophageal carcinoma alone. Discrepancies in these results can be attributed to differences in patient selection, different ethnic groups of patients, and possibly different 
sample sizes studied. As noted, their studies did not perform an association analysis for methylation and protein expression of the $h M L H 1$ gene, nor did they show a good correlation between gene methylation and protein expression with patients' clinicopathologic parameters, probably because of smaller sample sizes compared with that in our series.

In conclusion, our results suggest that aberrant expression of hMLH1 and hMSH2 protein is frequently associated with the presence of esophageal squamous cell carcinoma, suggesting that loss of these 2 DNA MMR proteins is involved in the tumorigenesis of this type of esophageal cancer. Protein expression of hMLH1 is a better prognostic predictor for resected squamous cell cancer of the esophagus than protein expression of hMSH2. Promoter methylation is one of the mechanisms responsible for the inactivation of $h M L H 1$ protein expression and is a potential molecular marker for squamous cell cancer of the esophagus. Further studies with cell line or resected tissue samples to elucidate other possible mechanisms of altered expression of the $h M L H 1$ and $h M S H 2$, including microsatellite instability of the genes, loss of heterozygosity, and alterations in mRNA transcription, might help us to understand better the role of MMR system in the tumorigenesis of squamous cell carcinoma of the esophagus.

We thank Dr Mark Ferguson at the University of Chicago for his review of this manuscript.

\section{References}

1. Herman JG, Merlo A, Mao L, et al. Inactivation of the CDKN2/p16/ MTS1 gene is frequently associated with aberrant DNA methylation in all common human cancers. Cancer Res. 1995;55:4525-30.

2. Graff JR, Herman JG, Lapidus RG, et al. E-cadherin expression is silenced by DNA hypermethylation in human breast and prostate carcinomas. Cancer Res. 1995;55:5195-9.

3. Herman JG, Latif F, Weng Y, et al. Silencing of the VHL tumorsuppressor gene by DNA methylation in renal carcinoma. Proc Natl Acad Sci U S A. 1994;91:9700-4.

4. Das PM, Singal R. DNA methylation and cancer. J Clin Oncol. 2004; 15:22:4632-42.

5. Leung SY, Yuen ST, Chung LP, et al. $h M L H 1$ promoter methylation and lack of $h M L H 1$ expression in sporadic gastric carcinomas with high-frequency microsatellite instability.Cancer Res. 1999;59:159-64.

6. Thibodeau SN, Bren G, Schaid D. Microsatellite instability in cancer of the proximal colon. Science. 1993;260:816-9.

7. Bronner CE, Baker SM, Morrison PT, et al. Mutation in DNA mismatch repair gene homologue hMLH1 is associated with hereditary non-polyposis colon cancer. Nature. 1994;368:258-61.

8. Papadopoulos N, Nicolaides NC, Wei YF, et al. Mutation of a mutL homolog in hereditary colon cancer. Science. 1994;263:1625-9.

9. Aaltonen LA, Peltomaki P, Leach FS, et al. Clues to the pathogenesis of familial colorectal cancer. Science. 1993;260:812-6.

10. Wang YC, Lu YP, Tseng RC, et al. Inactivation of $h M L H 1$ and $h M S H 2$ by promoter methylation in primary non-small cell lung tumors and matched sputum samples. Clin Invest. 2003;111:887-95.

11. Cai KQ, Albarracin C, Rosen D, et al. Microsatellite instability and alteration of the expression of hMLH1 and hMSH2 in ovarian clear cell carcinoma. Hum Pathol. 2004;35:552-9.

12. Puri SK, Si L, Fan CY, Hanna E. Aberrant promoter hypermethylation of multiple genes in head and neck squamous cell carcinoma. Am $J$ Otolaryngol. 2005;26:12-7.
13. Wu M, Semba S, Li D, Yokozaki H. Molecular pathological analysis of mucinous adenocarcinomas of the stomach. Pathobiology. 2004;71: 201-10.

14. Evans SC, Gillis A, Geldenhuys L, et al. Microsatellite instability in esophageal adenocarcinoma. Cancer Lett. 2004;212:241-51.

15. Merlo A, Herman JG, Mao L, et al. $5^{\prime} \mathrm{CpG}$ island methylation is associated with transcriptional silencing of the tumour suppressor p16/CDKN2/MTS1 in human cancers. Nat Med. 1995;1:686-92.

16. Kane MF, Loda M, Gaida GM, et al. Methylation of the hMLH1 promoter correlates with lack of expression of hMLH1 in sporadic colon tumors and mismatch repair-defective human tumor cell lines. Cancer Res. 1997;57:808-11.

17. Herman JG, Umar A, Polyak K, et al. Incidence and functional consequences of hMLH1 promoter hypermethylation in colorectal carcinoma. Proc Natl Acad Sci U S A. 1998;95:6870-5.

18. Veigl ML, Kasturi L, Olechnowicz J, et al. Biallelic inactivation of hMLH1 by epigenetic gene silencing, a novel mechanism causing human MSI cancers. Proc Natl Acad Sci U S A. 1998;95:8698-702.

19. Fleming ID, Cooper JS, Henson DE, et al. Digestive system: esophagus: In: Fleming ID, editor. AJCC cancer staging manual. 5th ed. Philadelphia: Lippincott Williams \& Wilkins; 1997. p. 65-9.

20. Herman JG, Graff JR, Myohanen S, Nelkin BD, Baylin SB. Methylationspecific PCR: a novel PCR assay for methylation status of $\mathrm{CpG}$ islands. Proc Natl Acad Sci U S A. 1996;93:9821-6.

21. Kaplan EL, Meier P. Nonparametric estimation from incomplete observation. J Am Stat Assoc. 1958;53:457-81.

22. The Lifetest procedure. In: SAS Technical Report: P-179, additional SAS/STAT procedures, release 6.03. Cary, NC: SAS Institute; 1988. p. 49-90.

23. Tzao C, Tsai HY, Chen JT, Chen CY, Wang YC. $5^{\prime} \mathrm{CpG}$ island hypermethylation and aberrant transcript splicing both contribute to the inactivation of the FHIT gene in resected non-small cell lung cancer. Eur J Cancer. 2004;40:2175-83.

24. Nie Y, Liao J, Zhao X, et al. Detection of multiple gene hypermethylation in the development of esophageal squamous cell carcinoma. Carcinogenesis. 2002;23:1713-20.

25. Hayashi M, Tamura G, Jin Z, et al. Microsatellite instability in esophageal squamous cell carcinoma is not associated with hMLH1 promoter hypermethylation. Pathol Int. 2003;53:270-6.

26. Kubo N, Yashiro M, Ohira M, Hori T, Fujiwara I, Hirakawa K. Frequent microsatellite instability in primary esophageal carcinoma associated with extraesophageal primary carcinoma. Int $J$ Cancer. 2005;20;114:166-73.

\section{Discussion}

Dr Stephen C. Yang (Baltimore, Md). Aberrant DNA methylation, as Dr Tzao has said, is the most common molecular lesion of the cancer cell. The most studied change of DNA methylation is the silencing of tumor suppressor genes, but now other cellular mechanisms are being investigated, such as alterations in DNA mismatch repair, as Dr Tzao and his colleagues have studied today. From a translational standpoint, defective DNA mismatch repair has important implications on the mechanisms of tumorigenesis and the clinical behavior of tumors and can be used as a target for anticancer agents, although tumor cells with defective mismatch repair display reduce sensitivity to the cytotoxic effects of DNA damaging agents, such as alkylating agents and cisplatin.

Over the past decade, there have been enormous efforts to understand the molecular mechanisms of defective mismatch repair in colon cancer, which have led to diagnostic tests to screen these gene mutations and have aided the oncologist to apply appropriate and specific regimens for tumor treatment. However, similar data are lacking in the esophageal cancer model.

Dr Tzao, my first question addresses your unique results of the high frequencies of hMLH1 and hMSH2 downregulation. Both are very rarely simultaneously downregulated in cancer. Either a tu- 
mor mutates or epigenetically alters hMLH1 or hMSH2, but this is one of the first reports I can find of both being downregulated with such high frequencies of $72 \%$ and $65 \%$, respectively. These frequencies are difficult to explain from a tumor biology point of view. In colorectal cancers, in which immunohistochemical analysis of these genes was first described by Lindor in 2002, he never saw absences of both hMLH1 and hMSH2 together in more than 1100 cancers. The absence rates of immunohistochemical expression in most other cell types are less than $30 \%$. Given your unprecedented results, what are your thoughts on the proposed mechanism of hMSH2 downregulation with hMLH1?

Dr Tzao. Thank you, Dr Yang, for the questions and important comments. What you have referred to is probably that colorectal cancer has a low incidence of hMLH1 expression. One of my collaborators, Dr Yi-Ching Wang, published an article on lung cancer lately in the Journal of Clinical Investigation, discussing both hMLH1 and hMSH2. They found a significant frequency in loss of expression of both of these 2 mismatch repair proteins. As far as I know, there are no data presenting the status of protein expression of these 2 proteins in parallel for squamous cell carcinoma in the same report. Those were what we observed. At this time, I have no good explanation as to the mechanism for loss of both of these 2 proteins. One might speculate that discrepancies could be attributed to differences in ethnic group, patient selection, or a different type of cancer studied.

Dr Yang. In your article you provide an explanation of why hMLH1 has reduced protein expression but provide no explanation for hMSH2. Did you look at $h M S H 2$ methylation? Is squamous cell carcinoma unique in being deficient in DNA mismatch repair activity?

Dr Tzao. I am sorry, can you rephrase that?

Dr Yang. Well, the first part of that question-you explained why hMLH1 has reduced protein expression, but you did not do that for hMSH2.

Dr Tzao. $h M S H 2$ methylation has been previously studied in other types of cancer, and it is rarely methylated, as reported by the majority of those published works. That is one of the reasons that we did not do the methylation assay for $h M S H 2$. Another reason for not performing this study actually is because our system was not working out well at the time of this report, but we will keep working on that to find out possible mechanisms that are responsible for aberrant expression of $\mathrm{hMSH} 2$ protein.

Dr Yang. Finally, I have a clinical question. How many of the patients in your cohort received adjuvant or neoadjuvant therapy? If they did, how does this affect your survival curves?

Dr Tzao. We were expecting to see a separate curve for the hMLH1 group, and actually, before 30 months, it appeared to separate out, but after that, it seemed to converge together, making the overall survival not significantly different. Our speculation to this observation is probably because of the selection of our patients because many of our patients were in the late stage, beyond stage IIB, and were generally given postoperative adjuvant therapy but did not improve in terms of survival. This might obscure a potential significant difference in survival. I believe that we need a larger sample size, including a more even distribution in early and late stages, to see whether there is a significant difference.

Dr Yang. Correct. That was one of the questions on that. On the left-hand panel, there was a divergence in the first 15 months.

Dr Tzao. Yes, in the first 30 months of follow-up.

Dr Yang. Therefore you cannot explain that by stage or other clinical factors, correct?

Dr Tzao. The explanation to your question, as I just mentioned, is probably because of our selection of patients.

Dr Yang. Again, I want to thank the Association for the privilege of discussing this article and congratulate you again on your findings.

Dr Tzao. Thank you very much.

Dr King F. Kwong (Baltimore, Md). Dr Tzao, I congratulate you and your colleagues on a fine foray into a very difficult area.

As you know, many genetic alterations and changes do not always correlate in terms of expression, and being able to look at the protein end of things really starts to get at the true mechanisms of how these genetic changes work.

I have 2 very quick questions. First, as you know, the incidence of adenocarcinoma is much more prevalent in our country, here as well as in some western countries, which is very contradistinct from in your country and in some of Asia. Have you looked at some of these changes-protein expression-and these genetic changes in adenocarcinoma? As you know, the difference between adenocarcinoma and squamous cell carcinoma is perhaps very different tumor biologies at play.

Dr Tzao. Thank you for the question.

In our country, it is interesting to tell you that we have more than $80 \%$ of patients with squamous cell carcinoma. Very rarely do we see esophageal adenocarcinoma. I have no explanation for why there is a rarity of adenocarcinoma at this time. This is why we focused on our patient population in which squamous cell carcinoma predominates.

Dr Kwong. So you have not looked at this in adenocarcinoma?

Dr Tzao. No. There has been a study by Evans and associates, and I think that is the only study on adenocarcinoma. In that study, they do not look at the promoter methylation for $h M L H 1$ but only the protein expression in this type of esophageal cancer.

Dr Kwong. Thank you. 
TABLE E1. Clinical information for patients undergoing esophagectomy for squamous cell carcinoma of the esophagus

\begin{tabular}{|c|c|c|c|c|c|c|c|c|}
\hline Stage & Patient no. & $\operatorname{Sex}(M / F)$ & $\begin{array}{c}\text { Age (y), } \\
\text { mean } \pm \text { SD) }\end{array}$ & $\begin{array}{c}\text { Surgical } \\
\text { approach } \\
\text { (TT/TH) }\end{array}$ & $\begin{array}{c}\text { RO } \\
\text { resection } \\
(\mathrm{Y} / \mathrm{N})\end{array}$ & $\begin{array}{c}\text { Induction } \\
\text { therapy } \\
(\mathrm{Y} / \mathrm{N})\end{array}$ & $\begin{array}{c}\text { Adjuvant } \\
\text { postoperative } \\
\text { therapy (Y/N) }\end{array}$ & $\begin{array}{c}\text { Median } \\
\text { survival } \pm \text { SE } \\
(\mathrm{mo})\end{array}$ \\
\hline I & 4 & $4 / 0$ & $55.8 \pm 15.5$ & $3 / 1$ & $4 / 0$ & $0 / 4$ & $0 / 4$ & $31.3 \pm 5.7$ \\
\hline IIA & $29^{*}$ & $32 / 3$ & $63.5 \pm 9.7$ & $26 / 3$ & $27 / 2 \dagger$ & $0 / 29$ & $2 / 27$ & $29.0 \pm 1.6$ \\
\hline IIB & 6 & $6 / 0$ & $62.8 \pm 9.4$ & $5 / 1$ & $6 / 0$ & $6 / 1$ & $5 / 1$ & $22.0 \pm 6.7$ \\
\hline III & $17^{*}$ & $17 / 0$ & $66.8 \pm 10.2$ & $17 / 2$ & $15 / 2 \ddagger$ & $14 / 3$ & $12 / 5$ & $15.0 \pm 5.1$ \\
\hline IV§ & 4 & $4 / 0$ & $53.5 \pm 9.1$ & $4 / 1$ & 4 & 0 & $3 / 1$ & $2.0 \pm 1.5$ \\
\hline
\end{tabular}

$T T / T H$, Transthoracic/transhiatal; SE, standard error. *Surgical mortalities: there were 2 among patients with stage IIA disease and 1 among patients with stage III disease, respectively. †These 2 patients were confirmed to have $\mathrm{R} 1$ resection postoperatively. $\ddagger$ One patient was considered as having $\mathrm{R} 2$ resection at the time of the operation, and the other was identified as having R1 resection postoperatively. §Two of them were staged as IVA because of a lower thoracic lesion with celiac nodal metastasis, and the other 2 were staged as IVB on account of a midthoracic lesion with perigastric ( $\mathrm{n}=1$ ) and celiac $(n=1)$ nodal involvement, respectively.

TABLE E2. Comparison between promoter methylation, protein expression of $h M L H 1$, and expression of hMSH2 protein and clinicopathologic features for patients undergoing esophagectomy for squamous cell carcinoma of the esophagus

\begin{tabular}{|c|c|c|c|c|c|c|c|}
\hline \multirow[b]{2}{*}{ Characteristics } & \multicolumn{3}{|c|}{ Methylation (hMLH1)* } & \multicolumn{2}{|c|}{ Protein (hMLH1)* } & \multicolumn{2}{|c|}{ Protein (hMSH2) $\dagger$} \\
\hline & Patients & - & $+(\%)$ & + & $-(\%)$ & + & $-(\%)$ \\
\hline Overall & 60 & 23 & $37(62)$ & 17 & $43(72)$ & 21 & $39(65)$ \\
\hline \multicolumn{8}{|l|}{ Staging } \\
\hline$I+I I$ & 39 & 19 & $20 \ddagger$ & 17 & $22 \S$ & 17 & 22 \\
\hline $\mathrm{III}+\mathrm{IV}$ & 21 & 4 & 17 & 0 & 21 & 4 & 17 \\
\hline \multicolumn{8}{|l|}{ TNM } \\
\hline $\mathrm{T} 1+2$ & 20 & 11 & 9 & 11 & $9 \|$ & 8 & 12 \\
\hline $\mathrm{T} 3+4$ & 40 & 12 & 28 & 6 & 34 & 13 & 27 \\
\hline No & 35 & 17 & $18 \emptyset$ & 17 & $18 \#$ & 13 & 22 \\
\hline N1 & 25 & 6 & 19 & 0 & 25 & 8 & 17 \\
\hline Mo & 56 & 22 & 34 & 17 & 39 & 20 & 36 \\
\hline M1 & 4 & 1 & 3 & 0 & 4 & 1 & 3 \\
\hline
\end{tabular}

TNM: $T$, tumor invasion; $N$, regional lymph nodes; $M$, distant sites (metastases). *These groups represent patients with alteration in the hMLH1 gene/protein. $\dagger$ These groups represent patients with hMSH2 protein. $\ddagger P=.024$ and $\S P<.0001$, respectively, between stage I+II and III $+\mathrm{IV}$. $\| P=.008$ between stage $\mathrm{T} 1+\mathrm{T} 2$ and $\mathrm{T} 3+\mathrm{T} 4 . \Phi P=.02$ and $\# P<.0001$, respectively, between N0 and N1.

TABLE E3. Concordance analysis between promoter methylation and protein expression of $h M L H 1$ in resected esophageal squamous cell carcinoma

\begin{tabular}{lcc}
\hline & & Promoter methylation \\
\cline { 2 - 3 } \multicolumn{1}{c}{ Protein expression } & $35(58.3 \%)^{*}$ & Unmethylated \\
\hline Aberrant & $2(3.3 \%) \dagger$ & $8(13.3 \%) \dagger$ \\
Normal & Concordant: $50(83.3 \%)^{*}$ & $15(25 \%)^{*}$ \\
Concordant vs discordant & Discordant: $10(16.7 \%) \dagger$ \\
\hline $\begin{array}{l}\text { Data were presented as actual numbers and percentages of cases in a total of } 60 \text { patients. *Concordant: methylated/aberrant and unmethylated/normal. } \\
\dagger \text { Discordant: unmethylated/aberrant and methylated/normal. } P<.001 \text { for correlation between promoter methylation and protein expression of the } h M L H 1\end{array}$ \\
$\begin{array}{l}\text { gene. }\end{array}$
\end{tabular}

